\title{
The biology of human parenting: insights from nonhuman primates
}

\author{
Dario Maestripieri* \\ Department of Psychology and Yerkes Regional Primate Research Center, Emory University, Atlanta, GA30322, USA
}

Received 20 September 1997; received in revised form 5 May 1998; accepted 13 May 1998

\begin{abstract}
Primate and human parenting have often been viewed as completely emancipated from neuroendocrine influences and primarily dependent on experience, social and cognitive processes. A review of recent findings of primate research on the neurobiological regulation of parental responsiveness, the causes of variability in parenting styles, and the determinants of infant abuse suggests that primate parenting is more sensitive to neuroendocrine mechanisms than previously thought. The findings of primate research can have important implications for human research and encourage the investigation of biological influences on human parenting. (C) 1999 Elsevier Science Ltd. All rights reserved.
\end{abstract}

Keywords: Endogenous opioids; Infant abuse; Hormones; Parental behavior; Oxytocin; Pregnancy; Primates; Serotonin; Temperament

\section{Introduction}

While an increasing number of studies have shown that human sexual and aggressive behavior are not completely emancipated from neuroendocrine variables [6, 100, 101], possible biological influences on human parenting remain generally uninvestigated. Most of our knowledge of the biological regulation of maternal behavior in mammals has been obtained from rats and sheep [43, 75]. In humans, however, parental behavior is affected by experiential, cognitive, and social variables to a greater extent than in rats and sheep, leading some psychologists to believe that human parenting has little in common with the caregiving behavior of other mammals [91]. The parental behavior of nonhuman primates (hereafter primates), particularly of those phylogenetically closest to us, i.e. Old World monkeys and apes, is more sensitive to experiential, cognitive, and social processes than the parental behavior of other mammals [78, 79]. In fact, despite obvious differences in the way parents care for their offspring in humans and other primates, many psychological and social mechanisms underlying parenting are likely to be very similar in humans and other primates [53, 59, 62, 63, 66]. Therefore, primates represent excellent animal models to investigate the potential role played by neuroendocrine mechanisms in regulating

\footnotetext{
* Corresponding author. Tel: + 1-404-727-4126; fax: + 1-404-7270372; e-mail: psydm@emory.edu.
}

human parenting and how these mechanisms interact with psychological and social processes [9].

In recent years, research on primate parenting has made significant progress in both conceptual complexity and sophistication of empirical analysis. Primate and human research on parenting currently overlap in at least three areas: the neuroendocrine regulation of parental responsiveness, the investigation of interindividual variability in parenting styles, and the determinants of infant abuse and neglect. In some cases, primate and human research have made parallel progress, while in others they have addressed complementary research questions. For example, whereas primate researchers have mostly concentrated their efforts on understanding the causes of individual differences in parenting styles, developmental psychologists have mostly investigated the consequences of these differences for child development.

The aim of this article is to review the recent findings of primate research on the neuroendocrine regulation of parental (maternal and paternal) responsiveness, the determinants of interindividual variability in parenting styles, and the determinants of infant abuse. In reviewing the relevant literature, I will discuss some similarities and differences in the research findings obtained with primates and humans and provide some examples of the contributions that primate research could make to our understanding of the regulation of human parenting. The article will be concluded by a final section on primate models of human parenting, in which I will review a recent biosocial model of parenting regulation and discuss some of its assumptions. 


\section{Neuroendocrine regulation of maternal responsiveness}

The few attempts that have been made to investigate neuroendocrine influences on human parenting have mostly focused on whether maternal responsiveness increases during pregnancy and is affected by hormonal changes. Both longitudinal and cross-sectional studies of women throughout their first pregnancy have shown that in most cases, women experience higher maternal feelings towards their own fetus at about 20-24 weeks of gestation and again after parturition [23, 25, 45, 47, 48]. Changes in maternal feelings during pregnancy do not appear to be correlated with changes in concentrations of hormones such as estradiol, progesterone, prolactin or cortisol $[23,25]$. In an early study, Fleming et al. [25] also reported no relationship between pregnancy hormones and maternal responsiveness in early postpartum days. In a subsequent study, however, mothers who maintained high levels of estradiol over the parturitional period also had higher feelings of attachment to their own infant in the early postpartum days [23]. Interestingly, the hormone that was most closely related to maternal behavior in the early postpartum period was not estradiol but cortisol. Higher salivary concentrations of cortisol were associated with more intense caregiving behavior in both primiparous and multiparous mothers [25, 26]. Furthermore, primiparous mothers with higher salivary concentrations of cortisol on day 1 postpartum were more attracted to their own infant's body odor and better able to recognize their own infants' odors than mothers with lower cortisol concentrations [26]. Maternal attraction to infant odors was also affected by previous experience with infants, and experience rather than cortisol, was the best predictor of variance in attitudinal measures of maternal responsiveness assessed with a questionnaire [26].

Fleming et al. [25] found only a weak positive correlation between women's feelings toward their own infants and feelings about infants in general, and no differences in liking for infants between pregnant and nonpregnant women. Similarly, Feldman and Nash [21] reported no differences between pregnant and nonpregnant women in their responsiveness to babies in a waiting room situation, and no differences in the time spent looking at slides depicting babies vs animal themes. Bleichfeld and Moely [5], however, found that heart rate acceleration in response to a pain cry of an unfamiliar infant increased during pregnancy.

The relationship between pregnancy and maternal responsiveness is complex and strongly affected by cognitive and emotional expectations concerning motherhood, which in turn depend on previous experience [11]. Nevertheless, the evidence available suggests that endocrine processes can account for some of the variability in maternal feelings and responsiveness to infants observed among human mothers.

In primates, a growing number of studies have shown that maternal responsiveness and maternal behavior are not emancipated from neuroendocrine mechanisms. In New World monkeys such as red-bellied tamarins (Saguinus labiatus) and common marmosets (Callithrix jacchus), there is evidence that steroid hormones influence both female responsiveness to young during pregnancy and the quality of maternal care during lactation. In a laboratory study of red-bellied tamarins, mothers whose infants did not survive had lower urinary concentrations of estradiol in the last week of pregnancy than mothers whose infants survived [80]. This difference was found in females without previous caregiving experience, but not in experienced mothers. In a study of common marmosets, nonpregnant females treated with estrogen and progesterone in concentrations similar to those of late pregnancy showed a significantly higher motivation to interact with infants than nontreated females [81]. Maternal motivaton was measured in an experimental apparatus in which females could press a bar to see an infant and simultaneously interrupt a tape recorder playing infant distress calls. However, among primiparous marmoset mothers with prior caregiving experience, individual differences in maternal behavior such as time spent carrying infants and latency to respond to neonate crying were not related to pre-partum sex steroid profiles, as estimated from urinary metabolites [82]. Pryce et al. [82] interpreted this finding by suggesting that the steroid priming of maternal behavior that occurs in the postpartum period may be 'all-or-none' rather than quantitative. Pryce et al. [82], however, used only 8 subjects for this study and it is possible that a significant association between variation in prepartum sex steroid profiles and postpartum maternal behavior could emerge with a larger sample size. This is suggested by the observation that in the two marmoset mothers with extreme values of maternal behavior, high maternal motivation was associated with a marked prepartum increase in estradiol and decrease in progesterone, while low maternal motivation was associated with the absence of either a prepartum increase in estradiol or a prepartum decrease of progesterone.

In Old World monkeys such as rhesus macaques (Macaca mulatta), earlier studies using individually housed animals failed to detect changes in female responsiveness to infants in relation to pregnancy or hormonal condition. For example, there were no significant differences in the behavior of intact, ovariectomized, and menopausal multiparous females during 60 min tests with an unfamiliar infant [35]. Similarly, there were no significant changes in infant-directed behavior when females were tested with an unfamiliar infant in different stages of pregnancy [27]. These negative findings, however, may have been an artifact of the experimental procedures used in these studies, and in particular of the stressful circumstances in which females and infants were tested. For example, when the same experimental procedures were used to compare infant-directed behavior among nulliparous females, intact and gonadectomized juvenile males and females, and pseudoermaphrodite females, most subjects displayed avoidance or fearful 
behavior toward unfamiliar infants and on no occasion did any of them retrieve and cradle infants, even when exposure to infants lasted a long period of time [28].

It is possible that the effects of steroid hormones on maternal responsiveness in macaques are more apparent in a complex social setting, where females can freely interact with other females' infants, than in a experimental situation forcing close proximity between an adult and an infant. Recent observations made in a large group of pigtail macaques (Macaca nemestrina) housed in an outdoor corral showed that the frequency with which females interacted with other females' infants increased during middle-late pregnancy [67]. A subsequent study replicated these findings in both pigtail and rhesus macaques, showing that the increased interest in infants during late pregnancy occurred in conjunction with an increase in estradiol and in the estradiol to progesterone ratio [70]. Pregnant females were not more interested in infants than nonpregnant or ovariectomized females, suggesting that hormones are not necessary for the expression of female responsiveness to infants. In fact, macaque females begin interacting with infants in their first year of life and continue to do so throughout their lifetime irrespective of changes in their reproductive condition [58]. The increase in responsiveness to infants during pregnancy, however, was observed in multiparous females, suggesting that maternal parity and experience do not override the effects of pregnancy hormones on responsiveness to infants. Moreover, the finding that ovariectomized females significantly increased their rate of interaction with infants after estrogen treatment provides further experimental evidence that maternal responsiveness is affected by steroid hormones independently of experience [70].

In the great apes, no studies have yet been conducted to investigate the effects of hormone administration on maternal responsiveness. However, preliminary correlational evidence obtained with chimpanzees (Pan troglodytes) and gorillas (Gorilla gorilla) suggests that steroid hormone concentrations during pregnancy predict maternal competence during early lactation. In one study of chimpanzees, Dahl et al. [12] measured ano-genital swelling during pregnancy as a marker of estrogen concentration and found that females with higher swelling scores were more likely to show competent maternal behavior and have healthy infants than females with lower swelling scores. In captive gorillas, high urinary concentrations of progesterone during late pregnancy were associated with higher postpartum maternal competence [2].

Hormones probably affect maternal responsiveness by priming central mechanisms that enhance recognition of and responsiveness to infant stimuli. In a model of neuroendocrine regulation of maternal behavior mostly derived from rat and sheep studies, Keverne [42, 43] has proposed that steroid hormones lack specific coding for maternal behavior. Steroid hormones, however, play an important role in the induction of maternal responsiveness by recruiting and synchronizing a wide range of neural and neurochemical systems influencing maternal behavior. The changes induced by steroid hormones may include enhancement of sensory perception and learning contingent upon parturition as well as activation of specific neurochemical systems such as the oxytocin and opioid systems.

The effect of cortisol on maternal behavior and attraction to infant odors in human mothers could be mediated by changes in general levels of arousal/attention or perceptual function similar to those proposed by Keverne. Furthermore, the activation of arousal during the postpartum period could result in either positive or negative reactions to the infant depending on the previous experience of the mother and contextual factors [22]. Alternatively, it is possible that cortisol per se does not affect postpartum behavior, but that cortisol simply acts as a marker for other neurochemical changes accompanying the activation of the hypothalamicpituitary-adrenal axis [26].

In Keverne's model [42, 43], the changes in the oxytocin and 3 -endorphin peptidergic systems accompanying pregnancy, parturition, and lactation address specific areas of the brain and are essential for maternal responsiveness to occur. Data from rat and sheep studies have shown that the administration of exogenous oxytocin after ovariectomy and estrogen priming can induce caregiving behavior in nonmaternal females [38]. These studies have also shown that oxytocin and oxytocin receptors increase at parturition both centrally and peripherally, and that blocking endogenous oxytocin can inhibit experimentally-induced maternal behavior [38]. Therefore, the nonprimate data suggest that oxytocin is one of the primary candidates for mediating the effects of estrogen on maternal behavior.

In humans, oxytocin may be involved in mediating some of the temporary changes in the personality profiles of breastfeeding women, and such changes could in turn affect interactions with the newborn. For example, in some studies, breastfeeding women have reported themselves to be calmer and more socially interactive than nonbreastfeeding women; basal oxytocin levels were correlated with levels of calm while oxytocin pulsatility was correlated with social attitudes [99]. Although these oxytocinmediated personality changes may promote positive interaction with the newborn, there is no clear evidence linking oxytocin to maternal responsiveness or parenting behavior.

The role of oxytocin in the regulation of parental responsiveness in primates is only beginning to be investigated. In a pilot experiment conducted with two nulliparous rhesus females, Holman and Goy [36] examined whether an intracerebroventricular injection of oxytocin affected responsiveness to infants. The two females were exposed to an unfamiliar infant in a cage $10 \mathrm{~min}$ after the injection of oxytocin or saline. The females sat near the infant, and watched, touched, and lipsmacked to the infant more frequently following oxytocin compared to saline administration. In no case, however, was more intense caregiving behavior observed, perhaps because of the environment in which the animals were tested. In another study, CSF levels 
of oxytocin measured in 10 multiparous rhesus females before, immediately after parturition, and 7 days postpartum were not correlated with mother-infant behaviors such as contact or grooming [10]. Taken together, these preliminary studies provide equivocal evidence concerning the role of oxytocin in regulating maternal responsiveness in primates.

In addition to oxytocin, a number of studies of primates and other mammals have implicated endogenous opioids in the development of the maternal and social bond and in the mediation of separation-induced distress [16, 40, 41, 44, 71, $72,74,76,87]$. In particular, it has been suggested that the activation of the $\beta$-endorphin system during late pregnancy and suckling may promote the positive affect arising from maternal bonds, whereas the pharmacological reduction of opioid activity may promote a central state comparable to that occurring when the safety of the offspring is threatened [76]. This hypothesis was supported by a recent study showing that the administration of the opioid receptor-blocker naltrexone to rhesus macaque mothers or infants increased their affiliative behavior and clinging after separation and reunion [41]. Similarly, the administration of naloxone to juvenile longtail macaques (Macaca fascicularis) resulted in an increase in the role played by juveniles in maintaining proximity to their mothers, and in soliciting grooming from them [71, 87]. One study of rhesus macaques, however, reported that naloxone administered to rhesus mothers led to a reduction in maternal restraining and grooming of the infant, rather than to an increase in maternal bonding as predicted by the opioid hypothesis [72]. Some methodological differences between this and other studies may be responsible for this dicrepancy. For example, the dose of naloxone used in this study $(0.5 \mathrm{mg} / \mathrm{kg})$ was lower than those used in other studies $(1 \mathrm{mg} / \mathrm{kg})$. Moreover, infant restraining simply reflects the mother's tendency to control her infant's activity and is not necessarily a measure of maternal affiliation or mother-infant bonding. In fact, other studies of macaques have found that infant abuse is associated with high levels of maternal restraining (see below).

In nonprimate mammals, other neurotransmitters such as noradrenaline, serotonin, and corticotropin-releasing-factor (CRF) have been implicated in the regulation of maternal behavior at the central level [43, 75]. Preliminary findings suggest that these neurochemical systems may play a role in primates as well $[10,19,49]$, but more research is needed before any firm conclusions can be drawn.

\section{Neuroendocrine regulation of paternal responsiveness}

In the only study to date investigating the endocrine correlates of paternal responsiveness in humans, Fleming et al. [24] compared the affective and endocrine responses of men and women to hunger and pain cries of newborn infants. Hormonal data were obtained from saliva and blood samples collected before and after exposure to the stimuli. Females were generally more alerted to infant cries and showed fewer negative reactions to them than males. Mothers and fathers responded to the cries with more negative reactions but also with greater sympathy and alertness than did nonparents. Moreover, mothers were more likely to respond differentially to the two types of cries, showing more sympathy to pain than to hunger, than were fathers. Interestingly, in fathers but not mothers, cries produced a temporary rise in testosterone. Mothers who were more sympathetic to the cries showed a greater reduction in cortisol over time than did the less sympathetic mothers. Mothers who responded more differentially to hunger vs pain cries had higher cortisol levels. Moreover, mothers who experienced the hunger or pain cries with reduced positive affect or the hunger cry with greater sympathy had higher levels of both cortisol and testosterone. Similar to mothers, fathers showed an inverse relation between cortisol levels and positive reactions to infant cries. However, opposite to mothers, low rather than high levels of testosterone were associated with fathers' feelings of sympathy to infant hunger cries. Moreover, unlike mothers, fathers who were more sensitive to the cry type and responded differentially to pain versus hunger cries had lower rather than higher testosterone levels.

Among parents, many of the relations between cortisol, testosterone, and responses to infant cries were affected by the parents' parity and prior experience interacting with infants, whereas other hormones such as estradiol, progesterone or prolactin did not have significant effects. Among nonparents, there were few correlations between hormones and affective responses to infant cries in women. However, consistent with the results obtained with fathers, men with lower testosterone levels responded more positively to infant cries. Altogether, these findings suggest that mothers and fathers show similar responses to infant stimuli, although their parental responsiveness may be affected by hormones in different ways. Interestingly, similarities between mothers and fathers have also been reported in their feelings and concerns about being temporarily separated from their children [14].

In primates, the neuroendocrine regulation of paternal responsiveness is generally uninvestigated, in part because in most species fathers make little or no contribution to parental care. However, in some species of New World monkeys such as tamarins and marmosets, fathers provide extensive parental care after birth. A recent study of one of these species, the cotton-top tamarin (Saguinus oedipus), has provided the first evidence that hormones may influence paternal behavior in primates [105]. In this study, experienced fathers had higher urinary concentrations of prolactin during the postpartum period than other males. However, experienced fathers had lower cortisol levels, suggesting that the postpartum increase in prolactin did not result from stress. Moreover, prolactin levels in experienced fathers were highly correlated with their previous parental experience and were consistently elevated before birth, 
DEMANDINGNESS

(a)

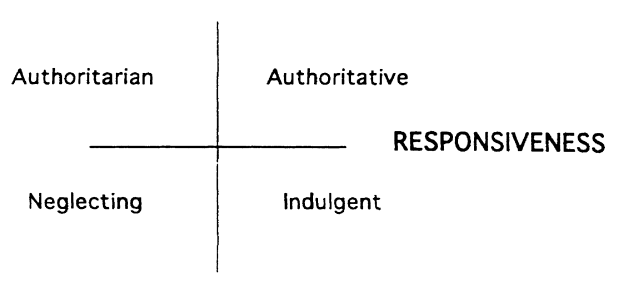

REJECTION

(b)

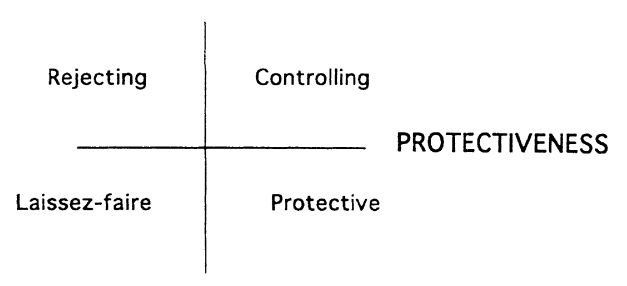

Fig. 1. (a) A two-dimensional model of human parenting style. (b) A twodimensional model of parenting style in Old World monkeys.

following birth, and after infants were weaned. The cause of the prepartum increase in prolactin was not clear, but may have been due to cues received from the pregnant female. Although these findings are clearly preliminary, they suggest that primates can provide the opportunity to investigate possible biological influences not only on maternal, but also on paternal responses to infant stimuli.

In general, the importance of a primate model to investigate the neurobiological regulation of parental responsiveness is quite obvious. Although human studies can produce correlations between behavioral and physiological variables, the assessment of cause-effect relationships between these variables is severely limited by the constraints imposed on manipulative research with humans. Primates allow us to conduct manipulative studies that would be impossible in humans and offer the opportunity to investigate how neurobiological mechanisms interact with experiential, cognitive, and social processes in the expression of parental responsiveness and behavior.

\section{Determinants of interindividual variability in parenting styles}

Developmental psychologists have long recognized that there are dramatic individual differences in parental attitudes and behavior toward children and that such differences are consistent over time and across different children. Although different models of parenting styles have been proposed, in most cases a wide range of parental behaviors reduce to two major dimensions, referred to as Demandingness and Responsiveness, Autonomy/Control and Love/ Hostility, Warmth/Hostility and Restrictiveness/Permissiveness [13]. In one of these models, the two dimensions of Demandingness and Responsiveness vary independently from each other and their combination results in four types of parenting styles known as Authoritarian (high in Demandingness and low in Responsiveness), Authoritative (high in both Demandingness and Responsiveness), Indulgent (low in Demandingness and high in Responsiveness), or Neglecting [low in both Demandingness and Responsiveness, 51; Fig. 1(a)]. Demandingness refers to the parent's willingness to socialize the child through supervision and discipline while Responsiveness refers to the parent's recognition of the child's individuality and needs.

In one of the few attempts to address the question of what causes individual differences in parenting styles, Belsky [3] identified three potential domains of determinants: (1) the parent's developmental history and temperamental characteristics; (2) the characteristics of the child; and (3) contextual sources of stress and support. The investigation of the relationship between the parent's temperament and his/her style of interaction with the child is a promising area of research that might especially benefit from the use of primate models. In both primates and humans, the concept of temperament is used to describe biologically determined consistencies in responsiveness to stressful challenges [8, 39]. In humans, however, most research on temperament has concentrated on children and we know little about the influence of the parent's temperament on his/her caregiving behavior.

Research on the causes of variability in parenting styles in primates has recently advanced at a faster pace than human research. Analyses of individual differences in maternal behavior in several species of macaques and in vervet monkeys (Cercopithecus aethiops) conducted with the Principal Components Analysis have shown that most variability occurs along the two orthogonal dimensions of Protectiveness and Rejection [20, 61, 86, 88, 92]. The dimension of maternal protectiveness includes variation in the degree to which the mother physically restrains infant exploration, initiates proximity and contact, and provides nurturing behaviors such as grooming. The dimension of maternal rejection includes the degree to which the mother limits the timing and duration of suckling, carrying, and contact. These dimensions combine to make four parenting styles, referred to as Protective (high in Protectiveness and low in Rejection), Controlling (high in both Protectiveness and Rejection), Rejecting (low in Protectiveness and high in Rejection), and Laissez-Faire [low in both Protectiveness and Rejection; Fig. 1(b)]. Differences in monkey parenting styles are consistent across infants and generations, and young females appear to learn their parenting style from their mothers, through direct experience in infancy or by observing their mothers with younger siblings [19].

Similar to human research, primate studies have shown that socio-demographic characteristics of mother and infant (e.g. the age, experience, and social status of the mother, and the sex of the infant) and contextual sources of support or stress (e.g. the presence of siblings, grandmothers, or potentially dangerous group members) can account for a 
significant fraction of variability in parenting styles [19]. However, the mother's style of reaction to stressful challenges, i.e. her temperament, also plays an important role.

A study of maternal anxiety in rhesus macaques provided preliminary evidence that the mother's emotional reactivity to stressful challenges can be a better predictor of variability in maternal protectiveness than other characteristics of mothers and infants or of their social environment. In this study, mothers who showed frequent behavioral signs of anxiety in response to interruption of contact with their infants and infant proximity to dangerous individuals scored higher in maternal protectiveness than less anxious mothers [53, 54]. More recently, Timme et al. [93] measured the temperament of rhesus macaque mothers with heart rate and plasma cortisol in baseline conditions and in response to capture. They found that the baseline heart rate was strongly correlated with behaviors reflecting excitability and irritability as well as with high rates of maternal rejection. In contrast, low levels of cortisol were associated with a relaxed parenting style.

Individual differences in temperament can also be detected at the neurochemical level. In both primates and humans, individual differences in the cerebrospinal fluid (CSF) concentrations of serotonin and dopamine metabolites (5-hydroxyindoleacetic acid or 5-HIAA, and homovanillic acid or HVA, respectively) tend to be stable within individuals, making them good candidates for proximal determinants of individual differences in temperament [31, 83]. Interestingly, in vervet monkeys CSF concentrations of 5-HIAA and HVA were good predictors of maternal protectiveness [19], and in rhesus macaques maternal 5-HIAA levels predicted the frequency of mother-infant contact [49]. Taken together, these data lend further support to the hypothesis that temperament is an important determinant of variability in parenting style.

Differences in temperament may account for differences in parenting styles not only among individuals of the same species, but also among different primate species. For example, among the closely related species of the genus Macaca, consistent differences have been reported for both behavioral and physiological reactivity to stressful challenges [8], and differences in parenting styles among these species appear to match their differences in temperament $[55,56$, 73].

Research on the determinants of variability in parenting styles in humans is limited by two main constraints, namely the difficulty of conducting longitudinal and cross-generational studies of parenting styles, and the difficulty of conducting experimental manipulations of developmental experiences and parental behavior. Given the similarities between the conceptualization of parenting style in primates and humans, primate research could make an important contribution to human research in this area. Primate research provides the opportunity to study parenting styles across the life-span and across generations within a much shorter time interval. Furthermore, it allows us to investigate the role of the parent's temperamental characteristics and experience with more invasive measures of temperament and with manipulations of the parent's developmental experience such as infant cross-fostering. Finally, the presence of clear differences in temperament and parenting styles among closely related monkey species provides a further research paradigm to investigate the relationship between these two variables without the confounding effects of individual experiential and cognitive processes.

\section{Determinants of infant abuse}

Child maltreatment is a complex and heterogeneous phenomenon potentially determined by multiple factors. According to recent etiological models of child maltreatment, the determinants of this phenomenon are likely to be found in the interactional process between parent and child, within the context of the family and the larger social structure and in light of the parent's developmental history $[4,7,103]$. In recent years, however, researchers and clinicians have also shown growing interest in the possible genetic determinants of abusive parenting and in its neuroendocrine consequences $[29,30,46]$. Preliminary studies have shown that child maltreatment has short- and long-term consequences for the activity of the hypothalamo-pituitary-adrenal axis similar to those observed for other forms of chronic stress in humans and animals. For example, one recent study reported that maltreated children with depressive symptoms showed a marked dysregulation of the diurnal pattern of cortisol secretion [30], while another study reported evidence of a reduction in cortisol reactivity in maltreated children related to an impairment in their social competence [29].

The notion that individuals who were abused as children have a higher than average probability of becoming themselves abusive parents $[15,102]$ is consistent with the hypotheses that there may be genetic influences on this phenomenon or that early stress associated with maltreatment can have long-lasting consequences for adult parental behavior. Constraints imposed by research with humans, however, have made it difficult to assess the role of genetic vs experiential factors in determining the intergenerational transmission of child maltreatment. Recent studies of infant abuse in monkeys suggest that primates could provide excellent animal models to investigate the mechanisms underlying the intergenerational transmission of infant abuse as well as the potential neuroendocrine correlates of abusive parenting.

In monkeys, infant abuse takes the form of hitting and biting the infant, dragging the infant on the ground by its tail, and other violent behavior such as stepping on the infant or throwing the infant a short distance [94, 97]. The consequences of abuse may vary from distress to serious injury and death. Preliminary data obtained in rhesus 
macaques indicate that, similar to abused children, abused infants have higher baseline levels of cortisol and ACTH than nonabused infants even long after the termination of abuse (Maestripieri and Plotsky, unpublished data).

Recent studies of large populations of rhesus macaques, pigtail macaques, and sooty mangabeys (Cercocebus atys) over a period of about 30 years have shown that abusive mothers abuse most of their infants regardless of their sex or birth order. In rhesus and pigtail macaques, abuse was more likely to occur in certain families than in others, and in all the three species, abuse was especially likely to occur in closely related females such as mothers and daughters, or sisters $[65,68,69]$. Therefore, these data suggest that infant abuse can be transmitted within families for several generations along the maternal line.

Studies of macaques have also shown that abusive mothers have a distinct temperamental profile and parenting style, scoring higher than control mothers in anxiety and maternal protectiveness (Japanese macaques, Macaca fuscata, [95, 96]; rhesus macaques, [60]; pigtail macaques, [64]). In one study of Japanese macaques, treatment of an abusive female with diazepam reduced significantly her maternal protectiveness as well as abusive behavior [96]. In rhesus macaques, abusive mothers typically had controlling parenting styles, namely they scored higher than nonabusive mothers in both maternal protectiveness and rejection [60]. Abusive mothers also received fewer approaches from other group members and tended to be more aggressive than control mothers. In pigtail macaques, infant abuse was most frequent in stressful situations such as those involving aggression or infant kidnapping [57, 64]. Abusive mothers, however, were not more likely than control mothers to find themselves in such situations, suggesting that they may be individuals particularly vulnerable to stress or with problems in emotion regulation [64]. High vulnerability to stress and emotional disorders are also relatively common among human abusive parents [63].

A number of primate and human studies have shown that a temperamental profile characterized by anxiety, impulsivity and low threshold for aggression is particularly common among individuals with lower serotonergic function, as measured by the CSF concentrations of the serotonin metabolite 5-HIAA [6, 31, 32, 83]. Interestingly, preliminary data obtained with rhesus macaques indicated that abusive mothers have lower CSF concentrations than nonabusive mothers (Maestripieri et al., unpublished data). Recent studies of macaques have also shown that the CSF 5HIAA concentrations of mothers and infants are highly correlated [33, 49], suggesting that serotonin-related personality traits show some degree of heritability. Serotonin-mediated personality traits, therefore, could be a potential mechanism for the intergenerational transmission of infant abuse in monkeys. The possibility that some dysfunction of the opioid system regulating maternal attachment may also be involved in infant abuse cannot be ruled out. Finally, it is also possible that the intergenerational transmission of abusive behavior relies on observing these patterns of behavior displayed by another individual (e.g. one's own mother) and then repeating the same patterns with one's own offspring. The crucial experiment to assess the relative importance of biological and experiential influences on infant abuse will involve cross-fostering female infants between abusive and nonabusive mothers and studying their parenting behavior when they give birth to their own infants. The results of this experiment and the further investigation of both the neuroendocrine and experiential correlates of infant abuse in monkeys could provide useful information for understading the causes and consequences of child maltreatment in humans.

\section{Primate models of human parenting}

There have been only a few attempts to integrate the findings of primate and human research in a model of parenting regulation. In recent years, the most comprehesive and integrated models of mammalian and primate parenting have been proposed by Pryce [77, 78]. In his latest biosocial model of the determinants of motherhood, Pryce [78] integrated the findings of research on the neuroendocrine regulation of maternal care in rats and sheep with those of primate and human research on maternal behavior and parenting styles, including infant abuse and neglect. In this model, parenting is viewed to vary on a continuum between the extremes of maximal care and infant abuse/ neglect (Fig. 2). The combination of a number of variables, ranging from genetic to social-environmental, can shift the balance toward one or the other extreme.

The extreme of maximal parental care and minimal neglect or abuse is represented by a hypothetical primate female with a genotype for a secure and sensitive personality, a developmental environment that included a secure attachment to an adequate caregiver and experience of 'play-mothering' (i.e. interaction with infants during adolescence), a stress-free pregnancy and postpartum period, optimal neurobiological priming and control, and considerable social support. Such a female will be highly attracted to her infant and made anxious by its crying, but will not averse to her infant or its novelty per se.

In contrast, the extreme of minimal parental care and maximal neglect and abuse is represented by a hypothetical primate female with a genotype for an insecure and neurotic personality, a developmental environment that included an insecure attachment to a caregiver and no experience with infants, a stressful pregnancy and postpartum period, a suboptimal neurobiological priming and control, and little or no social support. Such a female will be weakly attracted to her infant and will be averse to the infant including its crying, its physical burden, and its novelty.

Pryce's model of parenting regulation is attractive for its comprehensive integration of biological and social influences on parenting and its potential to generate many 


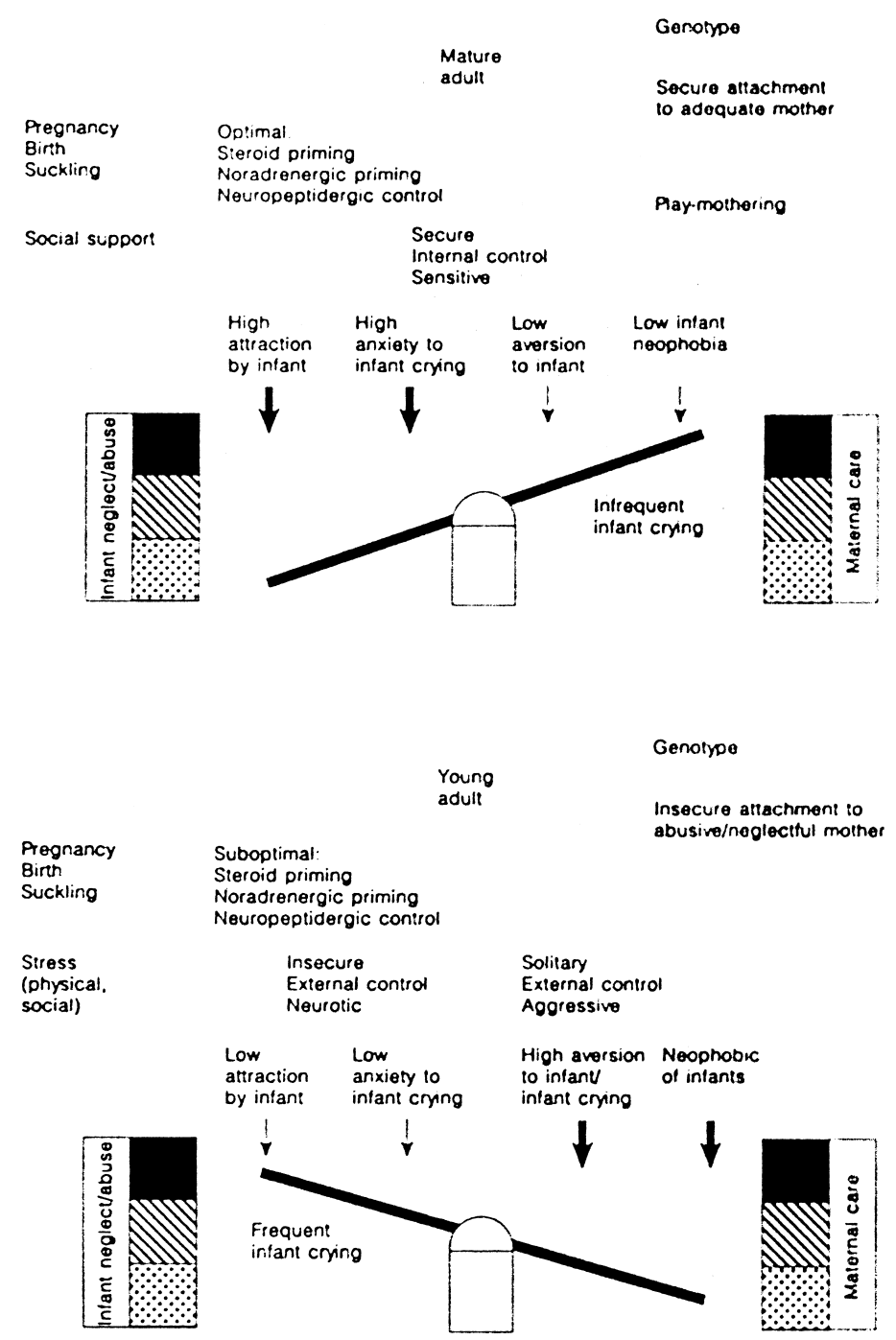

Fig. 2. Pryce's model of the reciprocal regulation of primate maternal care versus neglect and abuse. Reprinted with permission from Karger AG.

testable predictions. Similar to other previous animal models of mammalian parenting [22, 77], however, some of the central assumptions of Pryce's biosocial model are largely derived from nonprimate studies or from studies of primates conducted in highly artificial laboratory conditions. The conclusions of such studies have not been sufficiently validated by studies of primate parenting conducted in more naturalistic and complex social settings to be convincingly generalized to all primates including humans.

For example, the notion that primate females without hormonal priming and/or developmental experience with infants find neonates aversive is mainly derived from rodent studies and studies of socially deprived rhesus monkeys. In rats and other rodents, virgin females find pup odors aversive or anxiogenic and will actively avoid or kill unfamiliar pups [90]. Thus, an important component of the elicitation of maternal behavior through pregnancy, hormonal treatment, or sensitization involves the inhibition and suppression of aversive, anxiogenic, and cannibalistic responses elicited by pups. Although it is possible that the mechanisms inducing maternal behavior in rodents also operate in other mammals including primates, it cannot be ruled out that they represent a specific adaptation to the reproductive and social systems of rodents. Most rodents live in territorial social systems in which femalefemale aggression and infanticide play an important role [104]. Mothers themselves kill and cannibalize their own offspring when their territory has been invaded by an intruder and they have been unable to effectively defend their litter [52]. While female territoriality and competitive infanticide (i.e. killing other females' offspring) are not uncommon in other mammals, they appear to play little or no role in the social and reproductive strategies of extant primates and modern humans [89]. Thus, it is possible that the mechanisms underlying the induction of maternal behavior through the suppression of avoidant and infanticidal tendencies in rodents do not apply to primates.

Laboratory studies of socially deprived rhesus monkeys showed that when females were separated at birth from their 
mothers, raised in conditions of social deprivation, and individually housed with their infant in a small cage, there was a high incidence of inadequate maternal behavior including infant abuse and neglect [85]. Furthermore, the proportion of mothers displaying adequate maternal care increased with successive infants, suggesting that maternal behavior improved with experience. One study of rhesus monkeys in which individually housed nulliparous females were tested with strange infants showed that females avoided any interaction with the infants [35]. Taken together, these findings have led to the notion that, similar to rodents, nulliparous monkey females find newborns aversive and need experience and/or hormonal priming to overcome their aversion. These extrapolations, however, need to be made with caution for several reasons. First, one third of the rhesus mothers studied by Ruppenthal et al. [85] displayed adequate maternal care with their first-born infants, suggesting that their caregiving skills had not been significantly impaired by their developmental history. Second, while the occurrence of infant neglect decreased with successive infants, the occurrence of abuse did not. This finding, along with those obtained in group-living macaques [63], suggests that abuse does not result from lack of experience with infants and is not overcome through such experience. Third, most socially deprived mothers displayed maladaptive behavior in all behavioral interactions with conspecifics, ranging from mating to communication (see Ref. [63], for references), suggesting that their maladaptive infantdirected behavior could be best interpreted as one of the many aberrations induced by traumatic developmental experience rather than the result of a specific deficit in learning mothering skills. Fourth, when primate females are housed alone with an infant in a small cage, they are more likely to avoid or abuse the infant regardless of their previous experience, although young females may be more sensitive to this stressful situation than older females (see Ref. [63], for references). Thus, studies of socially deprived monkeys do not offer unequivocal evidence that nulliparous females find infants aversive or that experience with infants or hormonal priming is necessary to develop adequate caregiving skills.

When macaque females live in their natal social group surrounded by their family and other conspecifics of different sex and ages, they usually find newborns very attractive and not aversive. In fact, at 1 year of age, rhesus females are already more interested in infants than males are, even though at that age they are too small to hold or carry an infant properly [50]. If early female attraction to infants is the result of continuous exposure to other infants during the first year of life, it is not clear why the same attraction to infants does not develop in males as well. Female attraction to infants is unlikely to be the product of socialization because there is no clear evidence that males and females are treated differently by their mothers or other group members during the first year of life [19].

Although there is some evidence that, in vervet monkeys, young females modify and improve their caregiving skills through hands-on experience with infants [17], 'playmothering' is by no means a universal phenomenon in primates. For example, in a species closely related to the rhesus macaque, the stumptail macaque (Macaca arctoides), infants are attractive to older females, but are avoided by all group members except their mothers until they lose their infantile coat coloration, i.e. until they are no longer 'infants' [56]. In monogamous or solitary apes, such as gibbons or orangutans, the only opportunity provided to young females to interact with infants occurs if their own mothers produce siblings during the period in which young daughters remain close to their mother [37]. It is difficult to believe that all the young females who, for whatever reason, are deprived of such developmental experience with younger siblings will find their own firstborn infants aversive and will not possess some basic caregiving skills sufficient to raise them. More generally, it is hard to imagine the evolutionary reasons why primate females should perceive infant stimuli as aversive and not be biologically predisposed to display some basic caregiving skills.

These issues concerning some of the assumptions of current animal models of parenting emphasize the risk of extrapolating to humans the findings obtained from only a few animal species and in a few experimental settings. The study of primate parenting in different species and across different environmental conditions also suggests that we should use caution when we generalize the findings of some human studies. For example, one of the main assumptions of Pryce's model is that ' good human maternal behaviour can be defined as: spontaneous affection, sensitive responding to an infant's specific needs and behaviour, indulgent responsiveness (e.g. to crying); consistency; flexibility; absence of punitive disapproval and control; absence of aggression; security promotion; and awareness stimulation', (p. 3). Although the notion that an optimal parenting style or attachment pattern between parent and child exists is still quite common in the developmental literature, one of the main contributions of primate research to the study of human parenting has been the recognition that there may be more than one optimal parenting style [18, 34]. In fact, all of the four types of parenting styles found among monkeys could be adaptations to different characteristics of parents and infants, or to different environmental conditions. For example, it may be better for high ranking mothers to be laissez-faire and for low ranking ones to be protective, because their infants are exposed to different degrees of risk in the social environment [1]. Similarly, it may better for mothers to be rejecting or laissez-faire depending on the availability of food in the environment, because at times of shortage infants can significantly interfere with the mother's foraging ability [84]. The sex of the infant or the presence of social support could result in further adaptive variation in parenting styles in monkeys [18], and it is likely that some of these variables may induce different parenting styles in 
humans as well. Therefore, the primate data can be very important in generating models of human parenting that encompass not only variability from maximum to minimum, from best to worst, but also variability in adaptation to different circumstances.

\section{Conclusions}

Research with primates has now begun to elucidate the complex interaction between biological, psychosocial, and experiential factors in the regulation of parental behavior. Primate parenting has turned out to be more complex and more similar to human parenting than previously thought. The vast amount of information on the parenting styles of group-living monkeys gathered in the past three decades has prepared primate researchers to conduct experiments and test specific hypotheses concerning the determinants of variability in functional and dysfunctional parenting. Primate and human research could now proceed in parallel, each informing and complementing the other with theoretical and empirical contributions. The joint effort of primate and human researchers could result in new and exciting information on the determinants of individual differences in parental responsiveness and parenting style as well as significant progress in understanding the causes and consequences of child abuse.

\section{Acknowledgements}

The research cited in this article was supported by grants from the Leakey Foundation, the Biomedical Resources Foundation, the H.F. Guggenheim Foundation, NIH (R03-MH56328 and R01-MH57249), and in part by NIH grant RR-00165 to the Yerkes Regional Primate Research Center. The Yerkes Center is fully accredited by the American Association for Accreditation of Laboratory Animal Care. I thank Alison Fleming for providing access to unpublished data and two anonymous reviewers for helpful comments.

\section{References}

[1] Altmann J. Baboon mothers and infants. Cambridge, MA: Harvard University Press, 1980.

[2] Bahr NI. Environmental factors and hormones, their significance for maternal behavior in captive gorillas. In: Pryce CR, Martin RD, Skuse D, editors. Motherhood in human and nonhuman primates, biosocial determinants. Basel: Karger, 1995:94-105.

[3] Belsky J. The determinants of parenting. A process model. Child Dev 1984;55:83-96.

[4] Belsky J. Etiology of child maltreatment. A developmental-ecological analysis. Psych Bull 1993;114:413-434.

[5] Bleichfeld B, Moely BE. Psychophysiological responses to an infant cry, comparisons of groups of women in different phases of the maternal cycle. Dev Psychol 1984;20:1082-1091.

[6] Brown GL, Goodwin FK, Ballenger JC, Goyer PF, Major LF.
Aggression in humans correlates with cerebrospinal fluid amine metabolites. Psychiatr Res 1979;1:131-139.

[7] Cicchetti D, Toth SL. A developmental psychopathology perspective on child abuse and neglect. J Am Acad Child Adol Psych 1995;34:541-565.

[8] Clarke AS, Boinski S. Temperament in nonhuman primates. Am J Primatol 1995;36:1-23.

[9] Coe CL. Psychobiology of maternal behavior in nonhuman primates. In: Krasnegor NA, Bridges RS, editors. Mammalian parenting, biochemical, neurobiological, and behavioral determinants. New York: Oxford University Press, 1990:157-183.

[10] Cooke B, Higley JD, Shannon C, Lindell S, Higley HM, Suomi SJ, Linnoila M. Rearing history and CSF oxytocin as predictors of maternal competency in rhesus macaques. Am J Primatol 1997;42:102.

[11] Corter CM, Fleming AS. Maternal responsiveness in humans, emotional, cognitive, and biological factors. Adv Study Behav 1990;19:83-136.

[12] Dahl JF, Bard LA, Jones A, Gould KG. Perineal swelling during gestation and maternal competence in chimpanzees. Am J Primatol 1994;33:204-205.

[13] Darling N, Steinberg L. Parenting style as context. An integrative model. Psych Bull 1993;113:487-496.

[14] Deater-Deckard K, Scarr S, McCartney K, Eisenberg M. Paternal separation anxiety: relationships with parenting stress, child-rearing attitudes, and maternal anxieties. Psychol Sci 1994;5:341346.

[15] Egeland B, Jacobvitz D, Papatola K. Intergenerational continuity of abuse. In: Gelles J, Lancaster JB, editors. Child abuse and neglect, biosocial dimensions. New York: Aldine, 1987:255-276.

[16] Fabre-Nys C, Meller RE, Keverne EB. Opiate antagonists stimulate affiliative behaviour in monkeys. Pharm Biochem Behav 1982;16:653-659.

[17] Fairbanks LA. Reciprocal benefits of allomothering for female vervet monkeys. Anim Behav 1990;40:553-562.

[18] Fairbanks LA. What is a good mother? Adaptive variation in maternal behavior of primates. Curr Dir Psych Sci 1993;2:179-183.

[19] Fairbanks LA. Individual differences in maternal styles, causes and consequences for mothers and offspring. Adv Study Behav 1996;25:579-611.

[20] Fairbanks LA, McGuire MT. Mother-infant relationships in vervet monkeys. Response to new adult males. Int J Primatol 1987;8:351366.

[21] Feldman SS, Nash SC. Interest in babies during young adulthood. Child Dev 1978;49:617-622.

[22] Fleming AS, Corter C. Factors influencing maternal responsiveness in humans. Usefulness of an animal model. Psychoneuroendocrinology 1988;13:189-212.

[23] Fleming AS, Ruble D, Krieger H, Wong PY. Hormonal and experiential correlates of maternal responsiveness during pregnancy and the puerperium in human mothers. Horm Behav 1997;31:145-158.

[24] Fleming AS, Stallings J, Steiner M, Corter C, Worthman C. Cortisol and testosterone correlates of affective responses to infant cry and odor stimuli in new parents. Annual Conference of the Society for Behavioral Neuroendocrinology, Baltimore, MD, 1997.

[25] Fleming AS, Steiner M, Anderson V. Hormonal and attitudinal correlates of maternal behavior during the early postpartum period in first-time mothers. J Reprod Inf Psychol 1987;5:193-205.

[26] Fleming AS, Steiner M, Corter C. Cortisol, hedonics, and maternal responsiveness in human mothers. Horm Behav 1997;32:85-98.

[27] Gibber JR. Infant-directed behavior of rhesus monkeys during their first pregnancy and parturition. Folia Primatol 1986;46:118-124.

[28] Gibber JR, Goy RW. Infant-directed behavior in young rhesus monkeys, sex differences and effects of prenatal androgens. Am J Primatol 1985;8:225-237.

[29] Hart J, Gunnar M, Cicchetti D. Salivary cortisol in maltreated 
children, evidence of relations between neuroendocrine activity and social competence. Dev Psychopathol 1995;7:11-26.

[30] Hart J, Gunnar M, Cicchetti D. Altered neuroendocrine activity in maltreated children related to symptoms of depression. Dev Psychopathol 1996;8:201-214.

[31] Higley JD, King ST, Hasert MF, Champoux M, Suomi SJ, Linnoila M. Stability of interindividual differences in serotonin function and its relationship to aggressive wounding and competent social behavior in rhesus macaque females. Neuropsychopharmacology 1996;14:67-76.

[32] Higley JD, Mehlman PT, Taub DT, Higley TB, Fernald B, Vickers J, Suomi SJ, Linnoila M. Excessive mortality in young male nonhuman primates with low CSF 5-HIAA concentrations. Arch Gen Psychiatr 1996;53:537-543.

[33] Higley JD, Thompson WW, Champoux M, Goldman D, Hasert MF, Kraemer GW, Scanlan JM, Suomi SJ, Linnoila M. Paternal and maternal genetic and environmental contributions to cerebrospinal fluid monoamine metabolites in rhesus monkeys (Macaca mulatta). Arch Gen Psychiatr 1993;50:615-623.

[34] Hinde RA. Biological bases of the mother-child relationship. In: Call JD, Galenson E, Tyson RL, editors. Frontiers of infant psychiatry. New York: Basic Books, 1984:284-294.

[35] Holman SD, Goy RW. Behavioral and mammary responses of adult female rhesus to strange infants. Horm Behav 1980;14:348-357.

[36] Holman SD, Goy RW. Experiential and hormonal correlates of caregiving in rhesus macaques. In: Pryce CR, Martin RD, Skuse D, editors. Motherhood in human and nonhuman primates, biosocial determinants. Basel: Karger, 1995:87-93.

[37] Horr DA. Orang-utan maturation, growing up in a female world. In: Chevalier-Skolnikoff S, Poirier FE, editors. Primate bio-social development. New York: Garland, 1977:289-321.

[38] Insel TR. Oxytocin and maternal behavior. In: Krasnegor NA, Bridges RS, editos. Mammalian parenting, biochemical, neurobiological, and behavioral determinants. New York: Oxford University Press, 1990:260-280.

[39] Kagan J. Temperamental contributions to social behavior. Am Psychol 1989;44:668-674.

[40] Kalin NH, Shelton SE, Barksdale CH. Opiate modulation of separation-induced distress in non-human primates. Brain Res 1988;440:285-292.

[41] Kalin NH, Shelton SE, Lynn DE. Opiate systems in mother and infant primates coordinate intimate contact during reunion. Psychoneuroendocrinology 1995; 7:735-742.

[42] Keverne EB. Central mechanisms underlying the neural and neuroendocrine determinants of maternal behavior. Psychoneuroendocrinology 1988;13:127-141.

[43] Keverne EB. Psychopharmacology of maternal behaviour. J Psychopharmacol 1996;10:16-22.

[44] Keverne EB, Martensz ND, Tuite B. B-endorphin concentrations in cerebrospinal fluid of monkeys are influenced by grooming relationships. Psychoneuroendocrinology 1989;14:155-161.

[45] Klaus MH, Kennell JH. Maternal-infant bonding. St. Louis, MO: The CV Mosby Company, 1976.

[46] Krugman RD. Suppose it were a genetic disorder? Child Ab Negl 1997;21:245-246.

[47] Leifer M. Psychological changes accompanying pregnancy and motherhood. Genet Psychol Monogr 1977;95:55-96.

[48] Leifer M. Psychological effects of motherhood, a study of first pregnancy. New York: Praeger, 1980.

[49] Lindell SG, Higley JD, Shannon C, Linnoila M. Low levels of CSF 5-HIAA in female rhesus macaques predict mother-infant interaction patterns and mother's CSF 5-HIAA correlates with infant's CSF 5-HIAA. Am J Primatol 1997;42:129.

[50] Lovejoy J, Wallen K. Sexually dimorphic behavior in group-housed rhesus monkeys (Macaca mulatta) at 1 year of age. Psychobiology 1988;16:348-356.

[51] Maccoby EE, Martin JA. Socialization in the context of the family, parent-child interaction. In: Hetherington EM, editor. Handbook of child psychology. New York: Wiley, 1983:1-101.

[52] Maestripieri D. Functional aspects of maternal aggression in mammals. Can J Zool 1992;70:1069-1077.

[53] Maestripieri D. Maternal anxiety in rhesus macaques (Macaca mulatta). I. Measurement of anxiety and identification of anxietyeliciting situations. Ethology 1993;95:19-31.

[54] Maestripieri D. Maternal anxiety in rhesus macaques (Macaca mulatta). II. Emotional bases of individual differences in mothering style. Ethology 1993;95:32-42.

[55] Maestripieri D. Mother-infant relationships in three species of macaques (Macaca mulatta, M. nemestrina, M. arctoides). I. Development of the mother-infant relationship in the first three months. Behaviour 1994;131:75-96.

[56] Maestripieri D. Mother-infant relationships in three species of macaques (Macaca mulatta, M. nemestrina, M. arctoides). II. The social environment. Behaviour 1994;131:97-113.

[57] Maestripieri D. Infant abuse associated with psychosocial stress in a group-living pigtail macaque (Macaca nemestrina) mother. Am J Primatol 1994;32:41-49.

[58] Maestripieri D. Social structure, infant handling, and mothering styles in group-living Old World monkeys. Int $\mathrm{J}$ Primatol 1994;15:531-553.

[59] Maestripieri D. Assessment of danger to themselves and their infants by rhesus macaque (Macaca mulatta) mothers. J Comp Psychol 1995;109:416-420.

[60] Maestripieri D. Parenting styles of abusive mothers in group-living rhesus macaques. Anim Behav 1998;55:1-11.

[61] Maestripieri D. Social and demographic influences on mothering style in pigtail macaques. Ethology 1998;104:379-385.

[62] Maestripieri D, Call J. Mother-infant communication in primates. Adv Study Behav 1996;25:613-642.

[63] Maestripieri D, Carroll K A. Child abuse and neglect. Usefulness of the animal data. Psych Bull 1998;123:211-223.

[64] Maestripieri D, Carroll KA. Behavioral and environmental correlates of infant abuse in group-living pigtail macaques. Inf Behav Dev (in press).

[65] Maestripieri D, Carroll KA. Risk factors for infant abuse and neglect in group-living rhesus monkeys. Psych Sci 1998;9:143-145.

[66] Maestripieri D, Carroll KA. Maternal separation anxiety in human and nonhuman primates, its determinants and adaptive function. In: Troisi A, editor. The ethology of anxiety (in press).

[67] Maestripieri D, Wallen K. Interest in infants varies with reproductive condition in group-living female pigtail macaques (Macaca nemestrina). Physiol Behav 1995;57:353-358.

[68] Maestripieri D, Wallen K, Carroll KA. Infant abuse runs in families of group-living pigtail macaques. Child Ab Negl 1997;21:465-471.

[69] Maestripieri D, Wallen K, Carroll KA. Genealogical and demographic influences on infant abuse and neglect in group-living sooty mangabeys (Cercocebus atys). Dev Psychobiol 1997;31:175-180.

[70] Maestripieri D, Zehr JL. Maternal responsiveness increases during pregnancy and after estrogen treatment in macaques. Horm Behav (in press).

[71] Martel FL, Nevison CM, Simpson MJA, Keverne EB. Effects of opioid receptor blockade on the social behavior of rhesus monkeys living in large family groups. Dev Psychobiol 1995;28:71-84.

[72] Martel FM, Nevison CM, Rayment FD, Simpson MJA, Keverne EB. Opioid receptor blockade reduces maternal affect and social grooming in rhesus monkeys. Psychoneuroendocrinology 1993;18:307321.

[73] Mason WA, Long DD, Mendoza SP. Temperament and motherinfant conflict in macaques, a transactional analysis. In: Mason WA, Mendoza SP, editors. Primate social conflict. Albany, NY: SUNY Press, 1993:205-227.

[74] Meller RE, Keverne EB, Herbert J. Behavioural and endocrine effects of naltrexone in male talapoin monkeys. Pharm Biochem Behav 1980;13:663-672. 
[75] Numan M. Maternal behavior. In: Knobil E, Neill JD, editors. The physiology of reproduction, 2nd ed. New York: Raven Press, 1994:221-302.

[76] Panksepp J, Nelson E, Bekkedal M. Brain systems for the mediation of social separation distress and social reward. Ann NY Acad Sci 1997;807:78-100.

[77] Pryce CR. A comparative systems model of the regulation of maternal motivation in mammals. Anim Behav 1992;43:417-441.

[78] Pryce CR. Determinants of motherhood in human and nonhuman primates. A biosocial model. In: Pryce CR, Martin RD, Skuse D, editors. Motherhood in human and nonhuman primates. Biosocial determinants. Basel: Karger, 1995:1-15.

[79] Pryce CR. Socialization, hormones, and the regulation of maternal behavior in nonhuman primates. Adv Study Behav 1996;25:423473.

[80] Pryce CR, Abbott DH, Hodges JH, Martin RD. Maternal behavior is related to prepartum urinary estradiol levels in red-bellied tamarin monkeys. Physiol Behav 1988;44:717-726.

[81] Pryce CR, Döbeli M, Martin RD. Effects of sex steroids on maternal motivation in the common marmoset (Callithrix jacchus), development and application of an operant system with maternal reinforcement. J Comp Psychol 1993;107:99-115.

[82] Pryce CR, Mutschler T, Döbeli M, Nievergelt C, Martin RD. Prepartum sex steroid hormones and infant-directed behaviour in primiparous marmoset mothers (Callithrix jacchus). In: Pryce CR, Martin RD, Skuse D, editors. Motherhood in human and nonhuman primates. Biosocial determinants. Basel: Karger, 1995:78-86.

[83] Raleigh MJ, McGuire MT. Serotonin, aggression, and violence in vervet monkeys. In: Masters RD, McGuire MT, editor. The neurotransmitter revolution. Carbondale, IL: Southern Illinois University Press, 1994:129-145.

[84] Rosenblum LA, Paully GS. The effects of varying environmental demands on maternal and infant behavior. Child Dev 1984;55:305-314.

[85] Ruppenthal GC, Arling GL, Harlow HF, Sackett GP, Suomi SJ. A 10-year perspective of motherless-mother monkey behavior. J Abn Psychol 1976;85:341-349.

[86] Schino G, D'Amato FR, Troisi A. Mother-infant relationships in Japanese macaques. Sources of interindividual variation. Anim Behav 1995;49:151-158.

[87] Schino G, Troisi A. Opiate receptor blockade in juvenile macaques, effect on affiliative interactions with their mothers and group companions. Brain Res 1992;576:125-130.

[88] Simpson MJA, Howe S. Group and matriline differences in the behaviour of rhesus monkey infants. Anim Behav 1986;34:444459.

[89] Smuts BB, Cheney DL, Seyfarth RM, Wrangham RW, Struhsaker
TT, editors. Primate societies. Chicago, IL: University of Chicago Press, 1987.

[90] Stern JM. Maternal behavior, sensory, hormonal, and neural determinants. In: Brush FR, Levine S, editors. Psychoendocrinology. New York: Academic Press, 1989:105-226.

[91] Sternglanz SH, Nash A. Ethological contributions to the study of human motherhood. In: Birns B, Hay DF, editors. The different faces of motherhood. New York: Plenum Press, 1991:15-46.

[92] Tanaka I. Variability in the development of mother-infant relationships among free-ranging Japanese macaques. Primates 1989;30:477-491.

[93] Timme A, Rasmussen KL, Suomi SJ. Temperament, maternal and social behaviour in Cayo Santiago rhesus macaques. Behavioural and physiological relationships. Adv Ethol 1997;32:57.

[94] Troisi A, D'Amato FR. Is monkey maternal abuse of offspring aggressive behavior?. Aggress Behav 1983;9:167-173.

[95] Troisi A, D'Amato FR. Ambivalence in monkey mothering, Infant abuse combined with maternal possessiveness. J Nerv Ment Dis 1984;172:105-108

[96] Troisi A, D'Amato FR. Anxiety in the pathogenesis of primate infant abuse. A pharmacological study. Psychopharmacology 1991;103:571-572.

[97] Troisi A, D’Amato FR, Fuccillo R, Scucchi S. Infant abuse by a wild-born group-living Japanese macaque mother. J Abn Psychol 1982;91:451-456.

[98] Troisi A, Schino G, D’Antoni M, Pandolfi N, Aureli F, D’Amato FR. Scratching as a behavioral index of anxiety in macaque mothers. Behav Neur Biol 1991;56:307-313.

[99] Uvnas-Moberg K, Eriksson M. Breastfeeding, physiological, endocrine and behavioural adaptations caused by oxytocin and local neurogenic activity in the nipple and mammary gland. Acta Paediatr 1996;85:525-530.

[100] Virkkunen M, Rawlings R, Tokola R, Poland RE, Guidotti A, Nemeroff C, Bissette G, Kalogeras K, Karonen SL, Linnoila M CSF biochemistries, glucose metabolism, and diurnal activity rhythms in alcoholic, violent offenders, fire setters, and healthy volunteers. Arch Gen Psychiatr 1994;51:20-27.

[101] Wallen K. Desire and ability, hormones and the regulation of female sexual behavior. Neurosci Biobehav Rev 1990;14:233-241.

[102] Widom CS. The cycle of violence. Science 1989;244:160-166.

[103] Wolfe DA. Child abuse, implications for child development and psychopathology. Newbury Park, CA: Sage, 1987.

[104] Wolff JO. Population regulation in mammals. An evolutionary perspective. J Anim Ecol 1997;66:1-13.

[105] Ziegler TE, Wegner FH, Snowdon CT. Hormonal responses to parental and nonparental conditions in male cotton-top tamarins, Saguinus oedipus, a New World primate. Horm Behav 1996;30:287-297. 